\title{
Application of Low-Cost Optical PM Sensor for Monitoring of Particulate Matter Air Pollution in the Urban Environment: a Case Study in Esplanāde Housing Estate, Daugavpils City
}

\author{
Juris Soms \\ Dept. of Environmental Science and Chemistry \\ Daugavpils University \\ Daugavpils, Latvia \\ juris.soms@du.lv
}

\author{
Haralds Soms \\ Daugavpils secondary school No. 12 \\ Daugavpils, Latvia \\ haralds.soms@gmail.com
}

\begin{abstract}
The harmful health effects of airborne particulate matter (PM) pollutants are well-known. However, the spatial coverage of automated air quality observation stations of Latvian Environment, Geology and Meteorology Centre (LEGMC) is sparse. Therefore the capability for PM concentration detection was examined by using the low-cost optical PM sensor to improve the spatial resolution of environmental data. The aim of the study was to perform 24h/7d measurements of PM2.5 and PM10 concentrations during a period of one year and to identify air quality in Esplanāde housing estate, Daugavpils city. For data obtaining on the concentration of PM2.5 and PM10 particles measurements have been performed by optical sensor Nova SDS011; meteorological data were obtained using the database of LEGMC; for processing, analysis and visualization of obtained data statistical methods were applied. Evaluation of PM2.5 and PM10 daily average concentration variability in $\mathbf{2 0 2 0}$ indicates that air quality in the urban environment could be assessed as good. A wellexpressed statistical correlation between meteorological factors $\left(\mathrm{t}^{\circ} \mathrm{C}\right.$, relative humidity) and the average concentration of PM particles was not found. It highlights the necessity of further research.
\end{abstract}

Keywords - air pollution, environmental quality, particulate matter sensor, PM2.5, PM10.

\section{INTRODUCTION}

Air pollution is a complex process that brings various physical, chemical, organic and other pollutants into the atmosphere that in result negatively affect living organisms including humans, and the natural environment [1]. Among these pollutants fine particulate matter (PM) entails harm to human health even at relatively low concentrations; hence the concerns on issues dealing with public health are straightforward. According to definitions, airborne PM consists of a heterogeneous mixture of solid and liquid particles suspended in the air that varies continuously in size and chemical composition in space and time [2]. The PM itself can be classified in several ways. However, the aerodynamic diameter of a fine particle usually is the generally accepted criteria to describe its transferring ability in the atmosphere and ability to penetrate and deposit in the respiratory tract [3]. Usually, particles have been divided into two size categories as either (1) coarse particulate matter (PM10) with an aerodynamic diameter of $10 \mu \mathrm{m}$ or (2) fine particulate matter (PM2.5) with an aerodynamic diameter of $2.5 \mu \mathrm{m}$ [3]. Because of their small size, PM remains suspended in the air for a long time due to turbulence of the atmosphere and, as a result of a transfer by wind, can be transported far from their original sources - for hundreds or even thousands of km [4].

Air pollution by fine particulate matter (PM) is common in urban environments and currently is ranked among important environmental concerns [5]. This type of air pollution can be released into the atmosphere by various activities or processes from both anthropogenic and natural sources [6]. Anthropogenic sources and human activities associated with PM emissions are highly variable and include agricultural and industrial production, combustion of fuel in transportation, energy sectors, construction and quarrying works, wearing of the road pavement by traffic and re-suspension of road dust, mechanical abrasion of vehicle tires and brakes etc. [7]-[11]. In comparison, those PM emissions occurring naturally can be accounted for by such sources as forest fires, windblown dust, volcano 
Soms et al., Application of low-cost optical PM sensor for monitoring of particulate matter air pollution in the urban environment: a case study in Esplanāde housing estate, Daugavpils city

eruptions, spores and pollen from living vegetation, sea sprays etc. [12]-[13].

Considering that PM pollution can remain in the suspended state over long periods and can be transported over long distances, its harmful effect can cause a wide range of diseases. The researchers have been identified that exposure to high PM concentrations can cause numerous negative health effects including disorders in lung functions and lung cancer, asthma, exacerbation of chronic respiratory and cardiovascular diseases, premature mortality etc. [11], [13], [14]-[16]. Hence for the purposes of air quality monitoring and public health data analysis, PM10 and PM2.5 concentrations are being measured in very many countries. In Latvia the measurements of PM concentrations are carried out by automated air quality observation stations of Latvian Environment, Geology and Meteorology Centre (LEGMC). However, the spatial coverage of these stations is sparse, i.e. only in seven locations - two of these monitoring points are located in Riga, other five in Liepāja, Rucava, Rēzekne, Ventspils and Zosēni. At the same time, there is no monitoring of air quality in the second largest city in Latvia - Daugavpils. Considering that, the capability for PM concentration detection in a practical application was examined by using the low-cost optical PM sensor to monitor air quality in the urban environment and to improve the spatial resolution of environmental data.

\section{MATERIALS AND METHODS}

The aim of the present study was to perform continuous 24h/7d measurements of PM2.5 and PM10 concentrations during a period of one year and to identify air quality in Esplanāde housing estate, Daugavpils city. For the obtaining of data on the PM2.5 and PM10 concentrations, measurements have been performed by optical sensor Nova SDS011. This sensor corresponds to a category of DIY (Do It Yourself) measuring instruments because it can be easily assembled from module components. Besides, thousands of Nova SDS011 sensors are connected into the global network which is maintained by public platform openSenseMap at the Institute for Geoinformatics in Münster for storing and visualising open environmental sensor data [17]. The sensor was mounted in outdoor environment beside the premises of the Daugavpils University. The air intake nozzle of the sensor was put into a downward-orientated U-shaped plastic tube ensuring that the precipitation or small windblown physical objects cannot get into the sensor. The characteristics of the sensor are given in Table 1. The main advantages of such sensors are the low-cost pollution monitoring; easy operation; low energy consumption; high frequency of data recording (Table 1). Therefore such sensors are well suited for developing of widely dispersed sensor networks [18], [19].

TABLE 1 CHARACTERISTIC OF PM SENSOR USED IN THE RESEARCH

\begin{tabular}{|l|l|}
\hline Parameter & Characteristic \\
\hline Sensor model & SDS011 \\
\hline Manufacturer & Nova Fitness \\
\hline Approximate price (EUR) & 68 \\
\hline
\end{tabular}

\begin{tabular}{|l|l|}
\hline Dimensions $(\mathrm{mm})$ & $71 \times 70 \times 23$ \\
\hline Approximate weight $(\mathrm{g})$ & 50 \\
\hline Power supply voltage $(\mathrm{V})$ & 5 \\
\hline Working current $(\mathrm{mA})$ & 220 \\
\hline Detectable size range $(\mu \mathrm{m})$ & $0.3-10$ \\
\hline Size bins & Not available \\
\hline Estimated PMx concentration & PM2.5; PM10 \\
\hline Concentration range $\left(\mu \mathrm{g} / \mathrm{m}^{3}\right)$ & $0-999.9$ \\
\hline Measurement frequency & once per minute \\
\hline Data logging & To cloud server via WiFi \\
\hline
\end{tabular}

The sensor was pre-calibrated by the manufacturer, and, in addition, studies of scientific literature reveal that lowcost optical PM sensors generally well record the trend of PM concentration changes in the air and errors associated with overestimates or underestimates are within the range up to $7 \%$ [20]. Hence the results of this study can be utilised for the monitoring of air pollution by particulate matter. The measurements of both PM2.5 and PM10 concentrations (unit $-\mu \mathrm{g} / \mathrm{m}^{3}$ ) were performed every minute continuously 24h/7d during the 2020 monitoring year. All data on concentrations were transferred via $\mathrm{WiFi}$ and stored in the cloud server of the Institute for Geoinformatics in Münster [17].

In order to identify the correlation between weather conditions (air $\mathrm{t}^{\circ} \mathrm{C}$; relative humidity) and $\mathrm{PM}$ concentrations, selection and aggregation of meteorological data for station Daugavpils were done using the public database of LEGMC [21]. In that way, hourly values of meteorological data were downloaded for the whole period of monitoring and subsequently modified by Microsoft Excel into tables with columns containing the date, time and record of the parameter.

The data on measured PM concentrations were downloaded from the cloud server [17] as *.csv format files for each month of the monitoring period, obtaining four separate data rows - PM2.5 hourly max. concentrations, PM2.5 hourly average concentrations, PM10 hourly max. concentrations and PM10 hourly average concentrations, respectively. The *.csv data rows cannot be directly used for correlation and frequency analysis, therefore the Microsoft Excel functions TEXT TO COLUMNS, TRANSPOSE, MID, SUBSTITUE and CONCATENATE were applied to convert initial raw data into the tables with columns containing the date, time and record of the relevant concentration value.

To assess the level of air pollution by fine PM2.5 and PM10 particles and elucidate air quality in the urban environment of Esplanāde housing estate, the recorded concentrations were examined in respect to exceeding the thresholds specified by official regulations in Latvia (Table 2).

TABLE 2 INDEX OF AIR QUALITY AND CORRESPONDING THRESHOLD VALUES OF PM2.5 AND PM10 CONCENTRATION IN THE AIR [22]

\begin{tabular}{|l|c|c|}
\hline $\begin{array}{l}\text { Index of air } \\
\text { quality }\end{array}$ & $\begin{array}{l}\text { PM2.5 threshold } \\
\text { value }\left(\boldsymbol{\mu g} / \mathbf{m}^{\mathbf{3}}\right)\end{array}$ & $\begin{array}{l}\text { PM10 threshold } \\
\text { value }\left(\boldsymbol{\mu g} / \mathbf{m}^{3}\right)\end{array}$ \\
\hline Very good & $<10$ & $<20$ \\
\hline Good & $10-20$ & $20-40$ \\
\hline
\end{tabular}




\begin{tabular}{|l|c|c|}
\hline Moderate & $20-25$ & $40-50$ \\
\hline Poor & $25-50$ & $50-100$ \\
\hline Very poor & $50-75$ & $100-150$ \\
\hline Particularly poor & $>75$ & $>150$ \\
\hline
\end{tabular}

The correlation and regression analysis of the recorded data was performed following the standard procedures of environmental statistics and data analysis [23], [24].

Finally, interpretation of data obtained by low-cost optical PM sensor in the course of one year period monitoring of particulate matter air pollution in the urban environment was done.

\section{RESULTS AND DISCUSSION}

A. Monthly and intra-annual variability of PM2.5 and PM10 concentrations

The measurements of PM2.5 and PM10 concentrations by the sensor Nova SDS011 have been performed for one full year, obtaining 527040 records. After the processing of these data, the line charts as graphic representations of the variability of PM2.5 hourly max. and average concentrations, and PM10 hourly max. and average concentrations were analysed and compared on a monthly scale.

The results indicate that for both PM2.5 and PM10 hourly max. concentrations air quality threshold limits were quite often exceeded. In some months, e.g. in June, PM2.5 hourly max. concentrations for a short time exceed value $425 \mu \mathrm{g} / \mathrm{m} 3$. However, max. concentration reflect only the short-period temporarily peak values which do not characterize the overall situation of air quality. Therefore hourly average concentrations were analysed too as it is proposed by World Health Organization report on air pollution [2]. From this point of view, the quality of the environment in Esplanāde housing estate can be considered good - PM concentrations only temporarily exceeded air quality limit values during each month. The thresholds 25 $\mu \mathrm{g} / \mathrm{m}^{3}$ and $50 \mu \mathrm{g} / \mathrm{m}^{3}$ for PM2.5 and PM10 concentrations, respectively, were most often exceeded in March. The most feasible explanation of this effect is the impact of old grass burning in the spring and releasing particulate matter by smoke. The results of the research also reveal that PM concentrations can fluctuate greatly at a short temporal scale as either from one day to the next or even hourly. This is consistent with data given in the literature on issues of PM pollution [25].

To better estimate the quality of the environment, as well as to get a more complete understanding on the aspects of annual and inter-seasonal variability of the PM2.5 and PM10 concentrations, all hourly values of 2020 was aggregated into daily ones and plotted as a line chart. (Fig. 1). Daily average values allow us to assess air quality even better because they provide the information on the number of days when exceedance of threshold limits occurred, hence permitting to identify potential negative effects of the PM pollution associated with longer exposure to high PM concentrations [2]. Within the period of PM2.5 monitoring, the 24-hour threshold limit for the protection of human health $\left(25 \mu \mathrm{g} / \mathrm{m}^{3}\right)$ for this type of particulate matter pollution concentration in the air was exceeded 7 times (Fig. 1). Thus citizens were not exposed to the negative influence of PM2.5 particles for long period. As for PM10 particulates, the 24-hour threshold limit value for the protection of human health $\left(50 \mu \mathrm{g} / \mathrm{m}^{3}\right)$ was exceeded 14 times during the measurement period, particularly in autumn (Fig. 1). The EC Ambient Air Quality Directive [26] and World Health Organization [2] stipulate that the PM10 limit value should not be exceeded more than 35 times in a calendar year. Hence the results point out that air quality in the urban environment of Daugavpils could be assessed as good.

As for PM2.5 and PM10 particulates, the exceeding of limit values of average daily particulates concentrations mostly occurred in September and October (Fig. 1). This fact can be explained by the transboundary transferring of PM aerosols to Latvia by the wind from southern regions of the Russian Federation and eastern Ukraine, where extensive forest fires occurred in the autumn of 2020.

In general, during the warm period of the year from April till October concentrations of PM particulates are lower in comparison to the cold period (Fig. 1). This could be explained by the decrease in solid fuel combustion at residential dwellings during the warm season.

In order to find out the relationship between two components of the air PM pollution, the regression analysis of obtained data on average daily PM10 concentration values versus average daily PM2.5 concentration values has been performed. The results plotted in the bivariate scatter diagram (Fig. 2) show that with an increase of the average daily PM10 concentration values, the average daily PM2.5 concentration values also increase. Furthermore, this regularity is confirmed by the statistical analysis, which indicates that there is a statistically significant strong positive linear correlation between average daily PM10 concentration and average daily PM2.5 concentration in the air (Pearson's correlation coefficient $r=0.89$ at $p<0.01$ ). Such a close relationship can be explained by the fact that the group of PM10 particulates actually includes aerosols with an aerodynamic diameter $<10 \mu \mathrm{m}$ including also finer PM2.5 particles. However, due to differences in their formative processes, sources of provenance and composition, correlation is not perfect. From chart also follows that the distribution of points in the relationship diagram is uneven (Fig. 2). 
Soms et al., Application of low-cost optical PM sensor for monitoring of particulate matter air pollution in the urban environment: a case study in Esplanāde housing estate, Daugavpils city

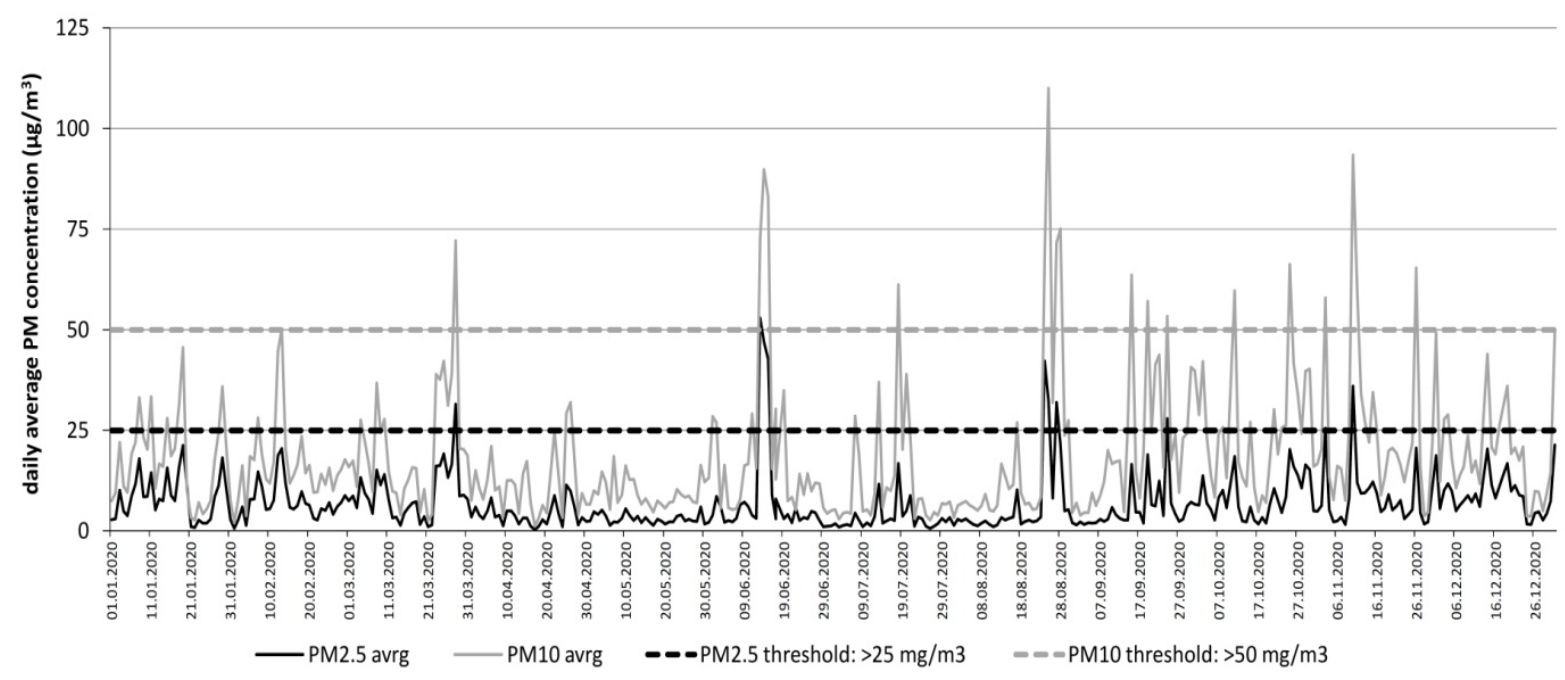

Fig. 1

Variability of daily average PM2.5 and PM10 concentrations in the air of Esplanāde housing estate in 2020 and the 24 hour threshold limits defined by LEGMC for air pollution by particulate matter.

Many points form a compact group at low concentrations - up to $20 \mu \mathrm{g} / \mathrm{m}^{3}$ and $10 \mu \mathrm{g} / \mathrm{m}^{3}$ for PM10 and PM2.5 particulates, respectively. Hence it indicates that the majority of recorded PM2.5 and PM10 daily concentrations in the air are low, under the limit value for the protection of human health.

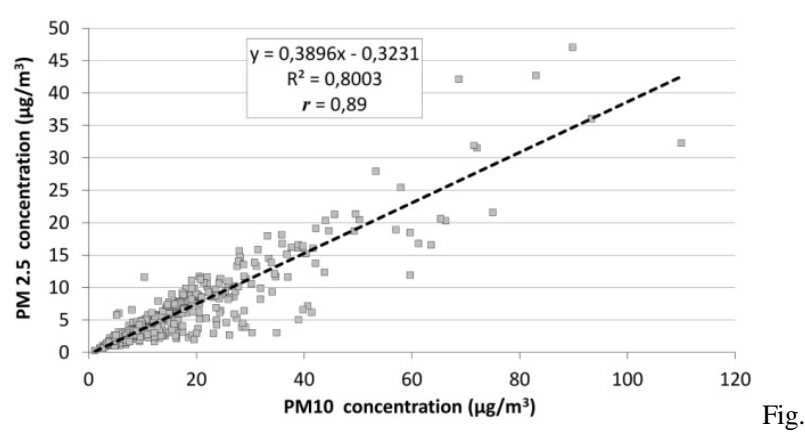

2. Relationship between average daily PM10 concentration and average daily PM2.5 concentration in the air of Esplanāde housing estate (Daugavpils) in 2020.

B. Variability in hourly concentrations of PM10 and PM2.5 particulates at a daily temporal scale

In the next stage data recorded by the PM sensor were analysed in order to find out the dynamics of changes in hourly concentrations of PM10 and PM2.5 particulates at a daily temporal scale for each month. For that statistical processing of data and distribution frequency analysis have been done. It allowed to identify when exceedance of limits specified for air quality indices [22] occurred at certain hours of the day. The PM10 and PM2.5 concentration daily distribution frequencies of each month subsequently were compared and inter-seasonal variability of ones was estimated (Fig. 3).

The distribution frequency histogram reveals that in the winter season there is a tendency of PM concentrations increasing at evening hours. This increasing is most pronounced from 17:00 till 20:00 (Fig. 3a; 3b). During these hours, air quality threshold values $25 \mu \mathrm{g} / \mathrm{m}^{3}$ for PM2.5 and $50 \mu \mathrm{g} / \mathrm{m}^{3}$ for PM10 are also most often exceeded. During the night time, PM concentrations decrease. However, limited pollution by fine particulates persists throughout the day (Fig. 3a; 3b).

The established regularity can be explained by the impact of many private residential houses in Grīva housing estate located just on the opposite bank of the River Daugava. In winter time residents of the aforementioned dwelling area burn up wood or other types of solid fuel in stoves and boilers, hence smoke and associate PM pollution plumes are transported across the river towards Esplanāde housing estate. This finding indicates that in winter time the main source of air pollution by PM particulates in the study area is the combustion of solid fuel at residential dwellings.

At the spring and autumn seasons distribution frequency patterns are similar to winter ones (Fig. 3c; 3d; 3g and 3h), i.e. there is a tendency of PM concentration increasing at evening hours. Notwithstanding, in the spring increasing is shifted to late evening hours due to longer daytime. In the autumn of 2020 more frequent exceedance of limits specified for air quality indices is associated with transboundary transferring of PM aerosols to Latvia by the wind from countries, where extensive forest fires occurred.

The distribution frequency pattern at the summer season indicates that there is no explicit regularity of the PM2.5 and PM10 concentration variability at a daily scale (Fig. 3e; 3f). The exceedance of limits specified for PM2.5 concentrations in the afternoon can be explained by the suspension of dust particles by the wind when the ground surface dries up. Besides, summer time is the period when the flowering of many plant species occurs, thus a significant amount of pollens enters in the atmosphere. The fact that pollen is a direct source of PM aerosols, particularly PM10 particulates, has been revealed in scientific studies on PM pollution sources [4]; [11]. In comparison to other seasons, however, air quality is much better. 
Environment. Technology. Resources. Rezekne, Latvia Proceedings of the $13^{\text {th }}$ International Scientific and Practical Conference. Volume 1, 223-229
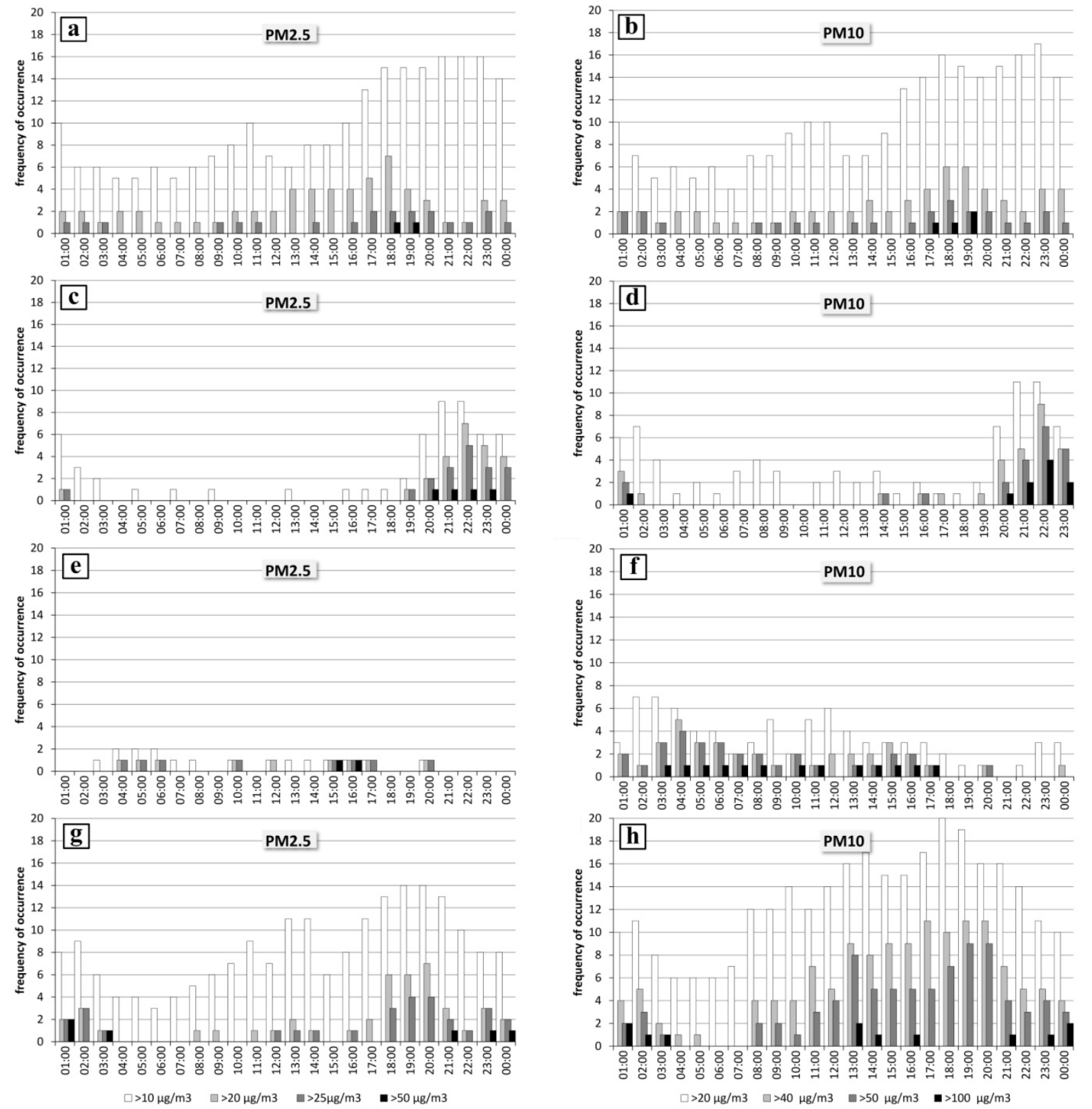

The frequency histograms showing inter-seasonal variability of the PM2 5 and PM10 concentration distribution at a daily temporal scale (hours o when exceedance of corresponding limits specified for air quality indices occurred): examples of the PM concentration distribution for the winter season (a and b; January as an example), the spring season (c and $\mathbf{d}$; April as an example), the summer season (e and f; July as an example) and the autumn season (g and $\mathbf{h}$; October as an example).

\section{Impact of meteorological factors on PM2.5 concentrations}

The regression analysis of obtained data on average daily PM2.5 concentration values versus values of meteorological factors (air $\mathrm{t}^{\circ} \mathrm{C}$; relative humidity) have been performed in order to elucidate possible relationships. In this case PM10 concentrations were not analysed due to fact that PM2.5 particulates have more harmful health effects then PM10 [11].

Theoretically, lower temperatures in the winter season should correlate with higher concentration of PM2.5 due to increase in fuel combustion as well as formation of stagnant atmospheric conditions [13], [27]. On the other hand, higher temperatures in the summer season should correlate with higher concentration of PM2.5 due to remobilization of dust by wind from dried soils and roads, as well as and enhancing secondary photochemical reactions in the atmosphere, which in turn increase the concentration of fine particles [13], [28]. Despite that, no consistent, well-expressed pattern has been found between air temperature and PM2.5 concentrations neither in the winter (Fig. 4a) nor in the summer (Fig. 4b). Thus statistical analysis of data for the winter season and scatter plot (Fig. 4a) indicate that there is statistically significant, but a very weak negative linear correlation between air temperature and PM2.5 concentration (Pearson's correlation coefficient $r=-0.24$ at $p<0.05$ ). 

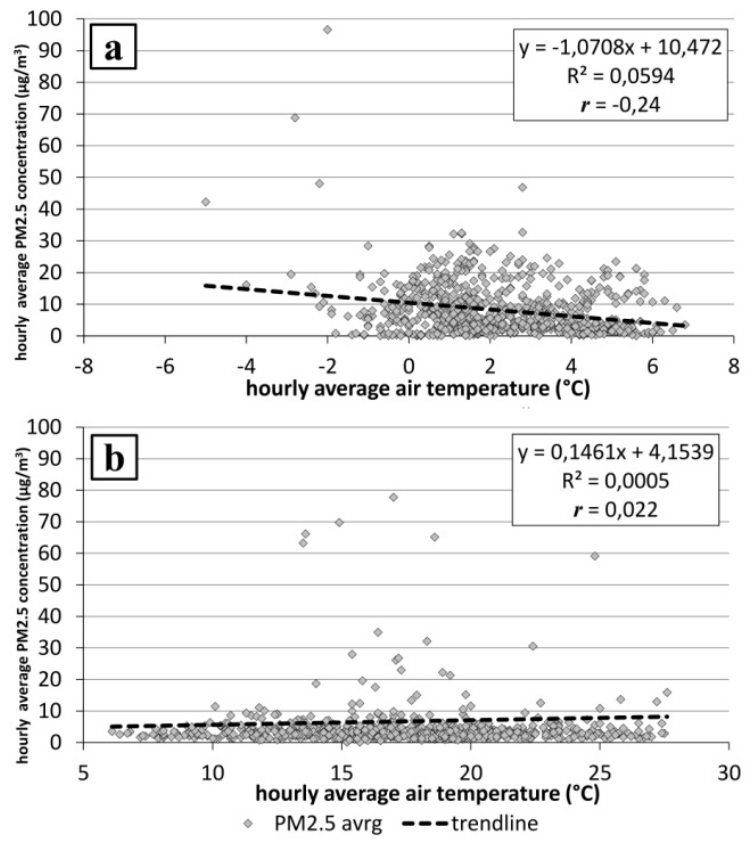

Fig.

4. Relationship between air temperature and PM2.5 concentration in the air of Esplanāde housing estate (Daugavpils) in the winter season (a) and the summer season (b) of 2020.

It is obvious that the highest PM2.5 concentration values correspond to lower temperatures, however, we have to take into account that winter of 2020 was unusually warm and it could have an effect on the results. Therefore the correlation has to be examined additionally in further research. Besides, the relationship in the summer period is not confirmed by the statistical analysis and scatter plot (Fig. 4b), which indicate that there is no statistically significant linear correlation between air temperature and PM2.5 concentration $(r=0.022$ at $p=0.55)$.

Similarly, the obtained results show that relative humidity also has no consistent correlation with PM2.5 concentrations neither in the winter nor in the summer (Fig. 5). As it follows from statistical analysis of data for the winter season and scatter plot (Fig. 5a), there is statistically significant, but a very weak positive linear correlation between relative humidity and PM2.5 concentration ( $r=$ 0.22 at $p<0.05)$.

However, the relationship in the summer period is not confirmed by the statistical analysis (Fig. 5b), i.e. there is no statistically significant linear correlation between air temperature and PM2.5 concentration $(r=0.042$ at $p=$ 0.27 ). Literature review reveals that some components of PM2.5 aerosols like organic compounds and dust particles decrease with higher humidity levels, while the concentration of others like sulphates in contrary increases [13], [28]. Furthermore, the higher humidity level can have a twofold impact: on the one hand, it can lead to the formation of microdroplets in the air causing the increase of aerosols concentration; on the other hand, it can lead to further condensation and to precipitation, which decreases overall PM2.5 particulates level [13], [29].
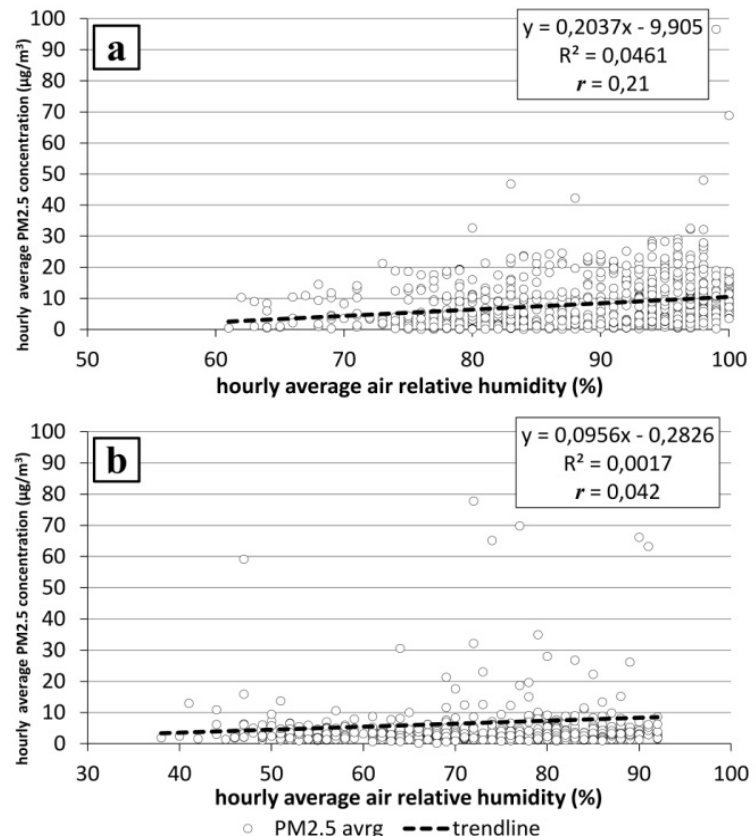

5. Relationship between air relative humidity and PM2.5 concentration in the air of Esplanāde housing estate (Daugavpils) in the winter season (a) and the summer season (b) of 2020.

\section{CONCLUSIONS}

The obtained results indicate the possibility to apply a low-cost optical PM sensor for monitoring of particulate matter air pollution in the urban environment, hence the main goal of the study has been achieved.

Within the period of PM particulates monitoring, the limit values for the protection of human health were exceeded less than 35 times which is specified in regulations. Thus citizens were not exposed to the negative influence of PM pollution for a long period and air quality in the urban environment could be assessed as good.

The main source of air pollution by PM particles is the burning of solid fuel at residential dwellings in Grivva housing estate, from where pollution plumes are transported towards Esplanāde housing estate.

In general, the decrease in solid fuel combustion at residential dwellings during the warm period of the year results in lower PM concentrations in comparison to the cold period.

There is a tendency of PM concentrations increasing at evening hours in the autumn, spring.

The decreasing of air quality can be caused by the transboundary transferring of PM aerosols to Latvia by the wind from other countries or regions.

A well-expressed statistical correlation between meteorological factors (air temperature, relative humidity) and the hourly average concentration of PM particles was not found. It highlights the necessity of further research. 


\section{REFERENCES}

[1] K-H. Kim, S.A. Jahan, E. Kabir, "A review on human health perspective of air pollution with respect to allergies and asthma. Environment International, vol. 59, pp. 41-52, Sept. 2013. https://doi.org/10.1016/j.envint.2013.05.007

[2] World Health Organization: Review of evidence on health aspects of air pollution -REVIHAAP project: Technical Report Copenhagen, Denmark: WHO Regional Office for Europe, 2013. [Online].

Available: http://www.euro.who.int/_data/assets/pdf_file/0004/193108/REV IHAAPFinal-technical-report.pdf [Accesed: Feb. 12, 2020]

[3] R. Esworthy, "Air quality: EPA's 2013 changes to the particulate matter (PM) standard,” Congressional Research Service 7-5700, No. R42934, p. 6, 2013

[4] K. Cheung, N. Daher, W. Kam, M.M. Shafer, Z. Ning, J.J. Schauer, C. Sioutasa, "Spatial and temporal variation of chemical composition and mass closure of ambient coarse particulate matter (PM10-2.5) in the Los Angeles area,” Atmospheric Environment, vol. 45 (16), pp. 2651-2662, 2011. https://doi.org/10.1016/j.atmosenv.2011.02.066

[5] P.L. Kinney, “Climate change, air quality, and human health,” Am J Prev Med, vol. 35 (5), pp. 459-567, Nov. 2008, https://doi.org/10.1016/j.amepre.2008.08.025

[6] R.W. Atkinson, G.W. Fuller, H.R. Anderson, R.M. Harrison, B. Armstrong, "Urban ambient particle metrics and health. A time series analysis,” Epidemiology, vol. 21, pp. 501-511, Jul. 2010. https://doi.org/10.1097/EDE.0b013e3181debc88

[7] A. Charron, R. Harrison, "Fine and coarse particulate matter on a heavily trafficked London highway: sources and processes," Environ Sci Technol, vol. 39 (20), pp. 7768-7776. Oct. 2005, https://doi.org/10.1021/es050462i

[8] T. M.C.M. de Kok, H. A.L. Driece, J.G.F. Hogervorst, J. J. Briedé, "Toxicological assessment of ambient and traffic-related particulate matter: A review of recent studies,” Mutation Research, vol. 613, (2-3), pp. 103-122, Nov.-Dec. 2006, https://doi.org/10.1016/j.mrrev.2006.07.001

[9] B. Srimuruganandam, S. Nagendra, "Source characterization of PM10 and PM2.5 mass using a chemical mass balance model at urban roadside,”Sci Total Environ, vol. 433, pp. 8-19. Sept. 2012, https://doi.org/10.1016/j.scitotenv.2012.05.082

[10] P. Kassomenos, S. Vardoulakis, A. Chaloulakou, G. Grivas, R. Borge, J. Lumbreras, "Levels, sources and seasonality of coarse particles (PM10-PM2.5) in three European capitals - Implications for particulate pollution control," Atmospheric Environment, vol. 54, pp. 337-347, Jul. https://doi.org/10.1016/j.atmosenv.2012.02.051

[11] K-H. Kim, E. Kabir, S. Kabir, "A review on the human health impact of airborne particulate matter," Environment International, vol. 74, pp. 136-143. Jan. 2015, http://dx.doi.org/10.1016/j.envint.2014.10.005

[12] C. Misra, M.D. Geller, P. Shah, C. Sioutas, P.A., Solomon, "Development and evaluation of a continuous coarse (PM10PM2.5) particle monitor,” J Air Waste Manage Assoc, vol. 51, pp. 1309-1317, Dec. https://doi.org/10.1080/10473289.2001.10464360

[13] N. R. Martins, G. C. da Graça, "Impact of PM2.5 in indoor urban environments: A review,” Sustainable Cities and Society, vol. 42, pp. 259-275. Oct. 2018 https://doi.org/10.1016/j.scs.2018.07.011

[14] E, Samoli, R. Peng, T. Ramsay, M. Pipikou, G. Touloumi, F. Dominici, R. Burnett, A. Cohen, D. Krewski, J. Samet, K. Katsouyanni, "Acute effects of ambient particulate matter on mortality in Europe and North America: results from the APHENA
Study,” Env Health Persp, vol. 116 (11), pp. 1480-1486, Nov. 2008. https://doi.org/10.1289/ehp.11345

[15] K. Katsouyanni, J.M. Samet, H.R. Anderson, R. Atkinson, A. Le Tertre, S. Medina, E. Samoli, G. Touloumi, R.T. Burnett, D. Krewski, T. Ramsay, F. Dominici, R.D. Peng, J. Schwartz, A. Zanobetti, "HEI Health Review Committee, 2009. Air pollution and health: a European and North American approach (APHENA). Research Report Health Effects Institute, vol. 142, pp. 5-90.

[16] H. Ather, S. Z. Ilyas, S. Agathopoulos, S. M. Hussain, A. Jalil, S. Ahmed, Y. Baqir, "Evaluation of adverse effects of particulate matter on human life,” Heliyon, vol. 7 (2), e05968, Febr. 2021. https://doi.org/10.1016/j.heliyon.2021.e05968

[17] openSenseMap, openSenseMap platform for open sensor data, 2020. [Online]. Available: https://opensensemap.org/about [Accesed: Jan. 01, 2020]

[18] N. Zikova, M. Masiol, D. Chalupa, D. Rich, A. Ferro, P. Hopke, "Estimating hourly concentrations of PM2.5 across a metropolitan area using low-cost particle monitors,” Sensors, vol. 17( 8), p. 1922, Aug. 2017. https://doi.org/10.3390/s17081922

[19] J. Hua, Y. Zhang, B. de Foy, X. Mei, J. Shang,Y. Zhang, I. D. Sulaymon, D. Zhou, "Improved PM2.5 concentration estimates from low-cost sensors using calibration models categorized by relative humidity," Aer Sc \& Techn, Feb. 2021, https://doi.org/10.1080/02786826.2021.1873911

[20] M. Badura, P. Batog, A. Drzeniecka-Osiadacz, P. Modzel, "Evaluation of Low-Cost Sensors for Ambient PM2.5 Monitoring," Journal of Sensors, vol. 2018, pp. 1-16, Oct. 2018. https://doi.org/10.1155/2018/5096540

[21] Meteorological network, Latvian Environment, Geology and Meteorology Centre (LEGMC) data base of meteorological data records, $2020 . \quad$ [Online]. https://www.meteo.lv/meteorologija-datu-meklesana/?nid=461 [Accesed: Dec. 31, 2020]

[22] Index of the air quality, Latvian Environment, Geology and Meteorology Centre (LEGMC), 2020. [Online]. Available: https://videscentrs.lvgmc.lv/lapas/gaisa kvalitates indekss [Accesed: Nov. 14, 2020]

[23] W. R. Ott, Environmental Statistics and Data Analysis, London: CRC Press, 1994, pp. 336

[24] Essential Environmental Science: Methods and Techniques,. Watts S. and Halliwel L. (eds.), London: Routledge, 1996, 544 pp.

[25] C. Johansson, M. Norman, L. Gidhagen, "Spatial and temporal variations of PM10 and particle number concentrations in urban air,” Environ Monit Assess, vol. 127 (1-3), pp.477-87, Sept. 2007, https://doi.org/10.1007/s10661-006-9296-4

[26] Directive 2008/50/EC of the European Parliament and of the Council of 21 May 2008 on ambient air quality and cleaner air for Europe, Official Journal of the European Union, vol. L 152, 11.6.2008, pp. 144 http://data.europa.eu/eli/dir/2008/50/oj

[27] R. Toro A., R. G. E. Morales S., M. Canales, C. Gonzalez-Rojas, M. A. Leiva G., "Inhaled and inspired particulates in Metropolitan Santiago Chile exceed air quality standards," Building and Environment, vol. 79, pp. 115-123, Sept. 2014. https://doi.org/10.1016/j.buildenv.2014.05.004

[28] B. M. Kim, J. Seo, J. Y. Kim, J. Y. Lee, Y. Kim, “Transported vs. Local contributions from secondary and biomass burning sources to PM2.5, “Atmospheric Environment, vol. 144, pp. 24-36, Nov. 2016. https://doi.org/10.1016/j.atmosenv.2016.08.072

[29] J. Luo, P. Du, A. Samat, J. Xia, M. Che, Z. Xue, "Spatiotemporal pattern of PM2.5 concentrations in Mainland China and analysis of its influencing factors using geographically weighted regression," Scientific Reports, vol. 7, No. 40607, pp. 1-14, Jan. 2017. https://doi.org/10.1038/srep40607 